\title{
UN NEGOCIO EDITORIAL ROMÁNTICO (ARIBAU Y WALTER SCOTT)
}

\author{
Ana M $M^{\mathrm{a}}$ FREIRE LÓPEZ \\ UNED (MADRID)
}

\section{Una colección de cartas}

Cuando hace algún tiempo, en el curso de una investigación sobre Juan Nicasio Gallego, leía las cartas en que se inscribe un proyecto editorial en el que estuvo involucrado, el de la traducción de las obras de Walter Scott al castellano, me llamó enormemente la atención el contenido y el tono de las mismas, por lo inusual entre literatos y más, si cabe, entre quienes pertenecieron al movimiento romántico o participaron de su espíritu. No conozco una correspondencia semejante, en la que se traten con tal lujo de detalles los pormenores de un negocio editorial, y en donde se pongan tan de manifiesto las aptitudes, los conocimientos y las estrategias para llevarlo a cabo, a la altura de 1828 , una época tan lejana que, sin embargo, en estas cartas resulta tan actual.

No quiero decir que no hayan existido antes del siglo XX proyectos editoriales planteados en esos términos, pero no ha quedado constancia escrita, debida en este caso a la circunstancia de que los amigos implicados en el negocio no residían en la misma ciudad. En Barcelona se encontraban Ignacio Sanponts (1795-1846), Ramón López Soler (1806-1836) y Juan Nicasio Gallego (1777-1853). Buenaventura Carlos Aribau (1798-1862), sin embargo, llevaba dos años viviendo en Madrid, adonde se había trasladado, por recomendación de Félix Torres Amat, para encargarse de la dirección de la casa 
comercial de Gaspar Remisa ${ }^{1}$, a quien, como es sabido, dedicó su conocidísima Oda a la patria².

Las cartas abarcan un período que va del 16-VII-1828, en que Aribau contesta a Sanponts, dándose por enterado del proyecto, y ofreciéndole su desinteresada colaboración y asesoramiento, hasta el $26-\mathrm{V}-1830^{3}$, en que se interrumpe esta correspondencia.

Estas cartas, aunque han sido manejadas por algunos investigadores en el curso de trabajos sobre la presencia de Walter Scott en España, que cito en la Bibliografía, continúan inéditas; sólo han sido utilizadas muy parcialmente, y nunca para estudiar lo que fue aquel negocio editorial, del que Fernández Montesinos (1955, pág. 74), remitiendo a Elías de Molíns.(1889 tomo I, 138a), y simplificando mucho las cosas, dijo que fracasó por culpa de la censura, que puso dificultades a la publicación de Ivanhoe.

A la luz de estas cartas, cuya extensión hace imposible reproducirlas íntegras en este artículo ${ }^{4}$, los hechos no fueron tan sencillos. Es verdad que la censura -estamos en los últimos años del reinado absoluto de Fernando VII- fue un esco-

' Cuenta Montolíu que «(...) el 1826, la vida d'Aribau sofrí una desviació que havia de fixar el seu desti d'una manera definitiva, ja que l'allunyava per sempre de Catalunya per a fer-li passar la resta dels seus dies a Madrid. Aquest any, per recomanació de Félix Torres Amat (...) Aribau entrà a la casa de comerç que tenia establerta a Madrid el català Gaspar de Remisa. No trigà aquest a descobrir les qualitats intel.lectuals i morals del seu nou empleat i li confià la direcció de les seves operacions mercantils.) (Montolíu 1936, 14).

${ }^{2}$ Me parece importante el párrafo en que Manuel de Montolíu relaciona esta famosísima composición de Aribau precisamente con Walter Scott: «Efectivament, l'Oda a la Pàtria, del nostre Aribau, que publica El Vapor en el número del 24 d'agost del 1833, és l'epileg de tot un procés anterior, $\mathrm{i}$, alhora, el preludi de tota una renaixença. La direcció d'El Vapor fou plenament conscient de la importància i de la significació de l'Oda d'Aribau, i donà solemnitat a la seva publicació afegint, en una nota al peu de la pàgina, aquesta presentació entusiasta: «La presentamos a nuestros lectores con el patriótico orgullo con que presentaría un escocés los versos de Sir Walter Scott a los habitantes de su país». Aquesta connexió que en la nota trobem entre el nom d'Aribau i el de Walter Scott sota el comú denominador del sentiment patriòtic, és d'una gran significació. ¿No és aquesta connexió prou expessiva per a fer-nos veure que en l'entusiasme per Walter Scott que agitava feia anys els nostres intel.lectuals, bategava latent un sentit pragmàtic, realista, un xic diferent de l'adoració purament platònica i idealista dels temps d'El Europeo?» (Montolíu 1936, 161).

${ }^{3}$ Manuel de Montolíu en op. cit. hace relación de estas cartas en el apéndice dedicado al epistolario de Aribau. Ya entonces se encontraban en la Biblioteca de Catalunya, procedentes del Archivo de Antonio Elías de Molíns, a quien se las había facilitado Lluis Rigalt, primo de Aribau, para que las utilizara al preparar su Diccionario. En total, las que tratan de este proyecto son 10 cartas de Aribau a Sanponts; 3 de Aribau a López Soler; 1 de Aribau a ambos; 8 de Sanponts a Aribau; y una de Sanponts a un amigo, en relación con Aribau.

${ }^{4}$ Sólo transcribiré los párrafos que considero verdaderamente imporantes en relación con el tema. En la transcripción, además de actualizar la acentuación y la ortografía, edito en cursiva los títulos de las obras literarias y de las cabeceras de los periódicos, que no siempre aparecen subrayados o resaltados en los textos manuscritos. 
1lo, pero no la causa del fracaso de un negocio mal llevado, que hubiera tenido un resultado muy diferente si se hubieran seguido los dictados de Aribau. Si las dificultades para obtener la licencia de publicación de Ivanhoe hubieran sido la causa del hundimiento de la empresa editorial, no se comprendería que en esta misma correspondencia Sanponts le diga a Aribau que Bergnes de las Casas ya ha conseguido la licencia para editar esa misma obra: «Ayer me dijeron que tu amigo Bergnes va a publicar el Ivanhoe que ya tiene la licencia» (22-VII-1829); máxime cuando Sanponts siempre había estado dispuesto a sacrificar el texto de Walter Scott con tal de que pasara el filtro de la censura: «Debo advertirte que estamos prontos a sacrificar, quitar o enmendar cualesquiera pasajes de la obra con tal que ésta pase en su totalidad, y para tratar y transigir sobre esto te damos amplias facultades. López te escribe sobre la parte literaria y había omitido esta circunstancia que me encarga te indique», escribía Sanponts, al exponer a Aribau las líneas maestras de «la empresa de sir Walter», como ellos la llamaron. Todavía más explícito será después de conocer las primeras objeciones de la censura, y la cita merece reproducirse, a pesar de su extensión:

He estado a verle [a López Soler] esta mañana y habiéndole comunicado las dificultades que ofrece el Templario y el Prior, hemos convenido a fin de zanjarlas en lo siguiente: $1^{\circ} \mathrm{El}$ Templario es un personaje tan esencial que no parece posible quitarlo de la escena, mucho más cuando toman una parte tan directa su Gran Maestre y hermano en el juicio de Rebeca celebrado en la Encomienda de la misma orden; pero, ya sea en el prólogo (que convendrá hacer para prevenir en los puntos delicados el juicio de una parte del público), ya sea en notas al pie, se podrá recordar que la orden en general mereció la extinción, sobre la cual se pronunciaron unánimes los Príncipes y la Sede apostólica, y advertir además que habiendo entrado en la orden Sir Brian de Bois Guilbert despechado de haber encontrado a su dama, al volver del oriente, entregada a otro caballero, llevó y conservó en ella los pensamientos y las costumbres del siglo que no pudieron sin embargo ser de algún desdoro a la austeridad del Gran Maestre y de otros recomendables compañeros en religión. $2^{\circ}$ Que el Prior es un carácter muy accidental a la obra y que si no basta haberle convertido de cortejo de las damas en jovial con todo el mundo y es preciso sacrificarlo del todo, sea él la víctima enhorabuena, y transfórmese en un caballero u otro quidam del país, que no sea sajón, pues lo es ya Cedrico, y se arrime más bien a normando, sin empeñarse a favor de éstos, porque, como dice López, hace un papel de pastelero. $3^{\circ}$ Que todas las expresiones de Vive Dios, Por $S$. Tal, \&c. y demás que ofenden en lo más mínimo por cualquier motivo se muden $o$ quiten a satisfacción. $Y$ últimamente pónganse notas $o$ suprímanse si así es preciso escenas parciales, como la del ermitaño. Lo que importa es que salga el hijo de Cedrico cojo, manco, o jorobado, a probar fortuna por esos mundos; pues a más de los gastos que hay hechos con él, sería difícil abrir la empresa con una obra que ya en su primer tomo presente tanto 
interés, testigo el mismo Kenilworth. Si el censor, ni por esas, se resuelve, podría retenerlo antes que dar un mal informe y veríamos si López nos hacía una reforma más radical de la obra. En cuanto a mí más quicro dificultades de parte de la censura, que ningún ataque después de publicado; que bien sería posible según se tomase la cosa. (25-II-1829).

Está claro que Sanponts temía más a la opinión pública que a la propia censura, como reiterará en su carta del 3 de junio: «Venga, pues, el Ivanhoe y veremos que pueda conciliarse con la opinión pública de nuestro país, que siempre le sería un terrible enemigo de cuyos embates no le libraría el despacho de la licencia del Juzgado».

\section{Los antecedentes del proyecto}

Las primeras traducciones de Walter Scott (1771-1832) editadas en castellano son de 1826, cuando aún vivía el novelista escocés. Ese año publicaba Piferrer en Barcelona El Talismán o Ricardo en Palestina, traducido por José Joaquín de Mora. Pero el primero en proponerse la traducción sistemática de las obras de Walter Scott al castellano parece que fue Alzine, que también en 1826 editaba en Perpiñán Ivanhoe, Los puritanos de Escocia y El enano misterioso. Su proyecto databa de dos años antes, pues en octubre de 1824 «imprimió un prospecto en el cual anunciaba la publicación de las obras completas de Walter Scott en 82 volúmenes en $12^{\circ}$ » (Marrast 1988, pág. 69). Sin embargo, «a mediados de 1826, a pesar de los anuncios de su catálogo, podemos pensar que Alzine había abandonado su ambicioso proyecto» ${ }^{5}$ (Marrast 1988, pág. 75 ), cuya finalidad, según Marrast, sería encubrir con Walter Scott la publicación de libros prohibidos.

Es muy probable que Aribau, admirador de Walter Scott, conociera el proyecto de Alzine. Ya en 1823, en el número 11 de El Europeo, se refería a la reciente publicación en París, por Gosselin, de las Obras completas de Walter Scott, con palabras muy semejantes a las del prospecto de Alzine, como ha señalado Marrast. Aribau era, según Montesinos, el primer crítico español que mencionaba a Walter $S \operatorname{cott}^{6}$.

${ }^{5}$ Núñez de Arenas afirma -y Marrast no tiene certeza- que en 1827 Alzine editó Quintin Durward; ese mismo año Pedro Beaume publicaba en Burdeos El oficial aventurero, traducido por Pablo de Jérica. y Jvanhoe salía en Nueva York, en tres volúmenes, editado por Behr y Kahl. En 1828 Pedro Beaume editaba en Burdeos El anticuario (según Marrast) y Rob Roy; y en Madrid Pedro Sanz La pastora de Lamermoor.

"No me parece verosímil la hipótesis de Marrast cuando apunta que puede ser Fontcuberta, y no Aribau, el autor del artículo de El Europeo. 
Pero si para Alzine aquel proyecto pudo ser una coartada, para el grupo catalán que entra en contacto con Aribau fue un proyecto editorial planteado como empresa económica.

\section{«La empresa de Sir Walter»}

Ignacio Sanponts y un socio, cuyo nombre oculta, tienen intención de editar una colección de obras de Walter Scott traducidas al castellano, y para ello Sanponts expone el plan a Aribau.

La empresa de Sir Walter está concebida bajo el siguiente plan económico. Se publicará un prospecto anunciando la Colección de las obras selectas do aquel autor a 8 ó 10 reales de vellón el tomo. La Empresa no se aventurará por ahora más que a la publicación del Ivanhoe. De los 4 tomos de esta novela hay ya traducido el primero (la primera mitad por D. Nicasio y la segunda por López), el segundo traducido por D. Nicasio y la mitad del tercero por López. La Empresa entrega a los traductores 1.500 reales por el primer tomo y 1.500 por el segundo. De los demás se hablará. Se queda la Empresa con la propiedad e imprime de su cuenta 1.000 ejemplares. Los gastos y ganancias se dividen en dos mitades, la una a favor de cierto sujeto que no suena y por él D. Narciso Menard a quien conocí por medio de López y tengo por sujeto muy honrado, y la otra a favor mío, de modo que los dos componemos la Empresa, quedando D. Nicasio y López con su paga solamente y teniendo trato con otros por razón del papel, \&c. Otro día te pondré un Estado de los demás gastos y te diré si podrás interesar $(\ldots)$

Aribau se ofrece a prestar su desinteresada colaboración, e incluso, si le admiten, a tomar parte en la empresa. Desde el primer momento se implica completamente.

Las cartas retratan a los corresponsales de cuerpo entero: un Aribau emprendedor, con sentido práctico y mente clara para los negocios 7 , y un Sanponts que no quiere correr riesgos de ningún tipo, y que teme a la opinión pública más que a la misma censura ${ }^{8}$; un Aribau optimista, con proyectos, y hombre de recursos, y un Sanponts que se repliega ante las dificultades.

? «Yo conozco el terreno, y Razola es hombre que también lo entiende»; «Dices que si hubiera tenido la licencia ya estuviera impreso el primer tomo. ¡Y el tercero se halla aún por traducir!»; «Si la empresa de Sir Walter Scott sale bien otras minas habrá que explotar»; «Lo que a ti te causa impresión es el desembolso que esto exigiría. Pero este temor es exagerado, pues se funda sobre un principio erróneos.

" «La Empresa no se aventurará por ahora más que a la publicación del Ivanhoe»; «Saliendo bien el lvanhoe se pasaría a otras obras del mismo autor; y de lo contrario se diría al público que pasa la Colección»; «Sobre pubiicar la impresión en los papeles franceses Gaceta de Bayona y la de Madrid hemos resuclto que no se haga por ahora, no sea que los franceses nos ganasen la delantera. 
En la primera carta de la colección (16-VII-1828) Aribau analiza con absoluta clarividencia el estado del ramo editorial o de librería en aquellos momentos, legándonos con ello un valioso testimonio:

Las mejores empresas de librería son actualmente las de obras que sirvan o puedan servir de texto de enseñanza. Esto daría lugar a excelentes especulaciones si el monopolio de la Junta de Inspección de Escuelas no se hubiese apoderado de este ramo. Sin embargo, acudiendo directamente a S. M. en solicitud de un privilegio exclusivo para una obra que presentase suma utilidad podría tal vez aprovecharse algo. Esto es lo que voy a hacer con un silabario que he arreglado.

Siguen después las obras de Religión, propias para el clero, que es quien en el día puede gastar más en libros. La Defensa del cristianismo por Frayssinous", la historia de la Reforma protestante ${ }^{10}$, la biblioteca de Religión que han publicado los PP. de Atocha" han tenido un despacho considerable.

No sé si acaso al artículo anterior hubiera debido preceder el de los Manuales prácticos para diferentes facultades y profesiones numerosas, tales como las obras de notaría, guías de alcaldes, Prácticas forenses: instrucciones para voluntarios realistas, obras prácticas de comercio \&. A esta clase reduzco un manual de la mujer hacendosa que estoy arreglando.

\footnotetext{
A. Razola no decirle tampoco que nos falta la licencia»; "Viendo que en caso de salir del Juzgado con bien el Ivanhoe será cosa extraordinaria, no estamos libres de que sea atacada la empresa y tenga disgustos después de publicado. Por consiguiente creemos que lo más prudente es retirar desde luego del Juzgado el memorial y originales presentados y que nos los vuelvas a remitir por conducto seguro»; «Ha quedado, pues, la empresa sin ningún traductor en ésta; nueva dificultad que con las que ofrecía la licencia del Ivanhoe hace desmayar enteramente a mi compañero y a mí. Yo creo que tú también te penetrarás de que estamos en la casi imposiblidad de pasar adelante en nuestro proyecto literario); «Todo otro pensamiento que deje paralizado el asunto como hasta aquí o que haga que se despache y publique a despecho de nadie (créeme) no nos conviene por ningún estilos».

${ }^{9}$ Efectivamente, la Defensa del cristianismo, o conferencias sobre la Religión, por el Excmo. Sr. Conde de Frayssinous, obispo de Hermópolis (...) traducidas al castellano, y dedicadas al Excmo. Señor Nuncio de Su Santidad en Madrid, por D. F. T. A. Chalumeau de Verneuil, se había publicado en Madrid, en la Imprenta de León Amarita, en cuatro tomos de alrededor de 500 páginas cada uno, en los años 1826 y 1827.

${ }^{10}$ Se refiere a la obra, en dos volúmenes, Historia de la reforma protestante en Inglaterra é Irlanda: en la cual se demuestra que dicha reforma ha empobrecido y degradado la masa del pueblo en ambos paises, escrita en una serie de cartas dirijidas [sic] á todos los ingleses sensatos y justos por William Cobbett, traducida del inglés al castellano por Alfonso Chalumeau de Vermeuil, Madrid, Imprenta y libreria de Sancha, 1827.

$"$ Los padres Basilio Antonio Carrasco y Juan Antonio Díaz Merino publicaron, entre 1826 y 1829 los 25 volúmenes, de una media de 400 páginas cada uno, de la Biblioteca de religión o sea Colección de obras contra la incredulidad y errores de estos últimos tiempos, Madrid, Imprenta de D. E. Aguado.
} 
Los libros de Medicina tienen también una salida muy regular, y si son de Medicina popular su despacho es asombroso. La obra de Le Roy se halla en Valencia en su $4^{a}$ edición, y esto que las 3 primeras han sido de un número considerable de ejemplares ${ }^{12}$.

Los libros de circunstancias tendrán siempre un despacho proporcionado a1 interés que excite la materia: lo difícil es obtener el permiso. El sitio de Misolongui ${ }^{13}$ y la descripción del imperio de Turquia ${ }^{14}$ han tenido grande aceptación, lo que me ha animado a formar una historia de la Guerra actual de la Rusia contra la Puerta, para publicarla inmediatamente de concluida. La oportunidad es la mejor circunstancia de esta clase de obras.

En materia de novelas pasó la moda, y ha de ser muy interesante la que obtenga un favor proporcionado a su mérito. La clase que antes leía este género de composiciones se halla pobre: los chascos que se ha llevado le han servido de escarmiento; y ya no compra sino con grande reserva. Sin embargo las novelas a poco coste, siendo de un autor conocido y de un título que llame la atención, podrán tener salida, como la han tenido El último Abencerraje, la pésima traducción de algunas de Marmontel \&c. (16-VII-1828).

Después de este análisis del panorama editorial, pasa a tratar de la propuesta que Sanponts le ha hecho Ilegar:

Descendiendo a examinar el proyecto de trabajos que me comunicó el amigo Borrás, debo decir:

$1^{\circ}$. Que las obras de Walter Scott (por supuesto que deberían escogerse las que aquí pueden pasar) tienen en España por defecto lo que en otros países es un mérito: están llenas de alusiones históricas, de pinturas fieles de costumbres, de expresiones propias de la época en que coloca la escena, circunstancias que no pueden ser saboreadas sino por quien esté algo más instruido que nuestros más comunes devoradores de Novelas. Infiero de aquí que las de este autor no podrán ser entendidas, ni por lo mismo apreciadas: que se encontrarán obscuros unos pasajes, impertinentes otros, y pesadísimos sus más hermosos

${ }^{12}$ Se trata de La medicina curativa ó La purgación: dirigida contra la causa de las enfermedades probada y analizada en esta obra, por Louis Le Roy, editada en Valencia por José Ferrer de Orga que, efectivamente, en 1828 daba al mercado la cuarta edición de esta obra de cerca de 500 páginas.

${ }^{13}$ La ciudad griega de Missolonghi había caído en poder de los turcos en 1826 , y en 1828 ya salía en Madrid, en la Imprenta de Sancha, la edición castellana, en trescientas páginas, de la Historia del sitio de Missolonghi, escrita en francés por Auguste Fabre; y traducida al castellano por D. ***. En Missolonghi había muerto Lord Byron en 1824, defendiendo la libertad por la que Grecia venía luchando desde 1821 .

${ }^{14}$ Debe de referirse a la Descripción geográfica, politica, militar, civil y religiosa del imperio otomano extractada de varias obras antiguas y modernas por Vicente Antonio Roger y Coma, obra de unas 400 páginas, editada en Madrid por Miguel de Burgos en 1827, que en 1829 tendría una segunda edición corregida y aumentada. 
diálogos. El talismán ya traducido ${ }^{15}$ es acaso una de las obras más proporcionadas, para la inteligencia de este país, y sin embargo de la grandiosidad de su objeto, del nombre de su autor, y del acierto de la traducción, ha sido recibida con frialdad según me dijo últimamente el librero Pérez encargado de su venta. Sin embargo, si este Correo Literario hablase mucho de Walter Scoth, podrían los aficionados prepararse bien a una buena acogida, y encontrar buenas sus producciones como de fe, y por boca de ganso.

$2^{\circ}$. La colección de las obras de Chateaubriand no podría ser completa. Las que faltan a traducir, o son de mediano interćs, o la censura no las pasaría; y las que ésta permitiría están ya en boga. Una segunda tradıcción de una misma obra es por sí misma una empresa muy arriesgada.

3'. El pensamiento de las causas célebres es el mejor de los tres, y presumo que tendría despacho como no pasase de dos volúmenes, no de gran costo. (16-VII-1828)

Aribau conoce el mercado y conoce al público. Analiza la psicología del lector medio de novelas, y pasa a tratar de las estrategias -verdadera operación de marketing editorial- para abrirle el apetito y despertarle el gusto por Walter Scott.

En la carta del 15 de octubre, Aribau se presenta a sí mismo como un buen partido para la empresa: «Yo puedo proporcionar a la empresa algunas ventajas». Afirma que tiene resortes para hacer hablar al Correo Literario, sabe cómo llegar a los posibles suscriptores, está bien relacionado con americanos de Burdeos y París que tienen negocios en Ultramar, conoce el modo de tratar con los libreros -no se refiere al «honrado y puntualísimo Razola», que aparece con frecuencia como persona de toda garantía en esta correspondencia--, sabe cómo «preparar la opinión a favor de Walter», y cómo hacer el prospecto y darle la publicidad necesaria, tirando no menos de 10.000 ejemplares. Todo esto lo pone a disposición de la empresa, aun cuando no llegara a formar parte de ella.

También tiene sus propias ideas en cuanto al arte de traducir. E1 18 de octubre, en carta a López Soler, se manifiesta partidario de suprimir pasajes que fuera de la lengua original carecen de sentido - «Una de las cosas que deseo ver es el modo con que vertiréis algunos pasajes: por ejemplo el primer capitulo de] Ivanhoe, en que se disputa si debe decirse puerco o tocino en normando o en sajón. En mi concepto todo esto y otras cosas semejantes deberían suprimirse porque fuera de su lengua original pierden todo el efecto.» (18-X-1828)-, aunque reconoce que en materia de traducción le falta la autoridad que sí cree tener en el aspecto empresarial. El 17 de diciembre le dirá que no está de acuerdo con que se supriman los epígrafes del texto original, porque dan amenidad a la obra.

${ }^{15}$ Se refiere, sin duda, a la traducción de José Joaquín de Mora, a la que antes me he referido. 
Además, como «la opinión pública debe prepararse a favor de Walter Scott, que no es muy conocido», le pide que redacte un artículo breve y conciso para el Correo Literario.

A partir de la carta a Sanponts del 5 de noviembre, Aribau va haciendo una seric de observaciones al plan, y es interesante comprobar que inmediatamente se da cuenta de los puntos que, de no cuidarse, podrían hacer fracasar la empresa, y que, como veremos, fueron los determinantes de su ruina. Aribau opina que no se puede ir solicitando licencias de impresión al paso que se van traduciendo los tomos de cada obra. Desde el punto de vista del suscriptor esto daria al traste con el negocio:

(...) para mí está evidentemente demostrado, que para sostener una suscripción de esta clase es preciso que los tomos se sucedan rápidamente en períodos determinados $e$ infalibles, y que por consiguiente ha de haber un caudal de materia preparado para que nunca falte original a la caja. Todo lo que pase de 15 días de intervalo de tomo a tomo es ahuyentar los suscriptores. Esto ocasionará precisamente algún mayor desembolso; pero sería peor cl que sc perdiese. (A Sanponts, 5-XI-1828).

Aribau cree necesario ese caudal en reserva, porque no pueden estar seguros de la regularidad de los censores, que además podrían retrasar las cosas con algún dictamen negativo, ni de los posibles retrasos de la imprenta, etc. Para acelerar el proceso, se ofrece a colaborar personalmente en las tareas de traducción, aunque siempre dispuesto a someter los resultados a la revisión de quienes tienen más autoridad que él en la materia ${ }^{16}$. También opina que una de tirada de 1.000 ejemplares es muy corta y que como mínimo ha de hacerse de 1.500: «de otra manera es miserable el negocio». Y añadirá (8-XI-1828) que no debe publicarse la primera novela hasta que no tengan suficientes materiales acumulados, ni darse publicidad al proyecto hasta que sea inminente el comienzo de la publicación. Adelantándose a posibles competidores, acaba de solicitar una entrevista con el traductor de La desposada o La novia de Lamermoor, que acaba de aparecer, pues ha leído en el prólogo que tal vez le sigan otras traducciones ${ }^{17}$.

16 «Tocante a que mi traducción al lado de las vuestras pudiera afear la obra, debo decir que procuraría imitaros, y por supuesto todo se sujetaría a vuestro examen. Por ninguna consideración ni etiqueta desechéis esta útil censura, pues conviene que en cuanto sea posible se vea en todo la impresión de una misma mano.» (Carta a López Soler de 5-XI-1828).

${ }^{17}$ EJ traductor de La desposada o La novia de Lamernoor que editó Sanz en I 828 respondía a las iniciales D. L. C. B. Según el testimonio de Sanponts, a López Soler no le gustó: «López encuentra poco animadas las traducciones del Ricardo y de La desposada. Creyó que el traductor de ésta era un viejo. La energía de la lengua inglesa aviva lo que en nuestro idioma queda desmayado si no se lo da más fuego.) (6-XII-1828). 
E1 22 de noviembre Aribau, ya admitido como parte de la empresa con un tercio del capital, manifiesta por primera vez su inquietud ante el ritmo con que se están llevando las cosas: «Estoy temblando si no nos apresuramos». Más audaz y emprendedor que Sanponts, procura desvanecer los temores de éste a un mayor desembolso porque, si las cosas van bien, como esperan, ya se amortizarán los gastos. También opina que conviene alternar novelas largas con otras más breves que puedan darse a la imprenta cuando haya problemas de continuidad. Y sugiere que Sanponts podría tratar con los comisionados de Valencia y Zaragoza, mientras que todos los demás de España deberían depender del de Madrid.

El contenido y el tono de la carta del 6 de diciembre revelan su impaciencia $y$ el temor de que otro editor se les adelante.

Mi querido Samponts. Este correo esperaba con ansia carta tuya, y el no haberla recibido me tiene con cuidado. Los momentos urgen: tenemos traducidos dos tomos del Ivanhoe: hasta que tengamos lo restante, como si nada tuviésemos. Entretanto, cada vez que cojo las gacetas, o el Diario, o el Correo Literario estoy temblando, pues a cada línea temo encontrar un rival de nuestra empresa más madrugador. Tengo entendido que Burgos ha animado a un joven a ensayarse en la traducción de Sir Walter Scott, y que ha empezado sus trabajos. Los novelistas de Valencia, ese Cabrerizo, y otros no sé cómo no han dado en esta idea, sobre la cual cuanto más reflexiono mayores esperanzas fundo. Por Dios, que alomenos sepa yo si he de traducir el $4^{\circ}$ tomo del Ivanhoe, pues en caso de que así debiese ser, y ayer lo hubiera sabido, mañana y pasado mañana hubiese aprovechado de las festividades para desbozar dos capítulos. Por Dios, mi querido Samponts, no perdamos tiempo y dinero, que una y otra cosa se perderán indudablemente si vamos a este paso. Espero tu contestación con la mayor impaciencia; pues tengo en este momento preparada la censura de manera que podrán sucederse rápidamente tomos a tomos si los hubiese. Adiós y calma el cuidado de tu buen amigo

B. C. Aribau

Él sí que se ha movido. Ha empezado a traducir por su cuenta El oficial aventurero, ha hablado con el traductor de La desposada para atraérselo a la empresa, pues es mejor esto que tenerlo como rival, e incluso ha decidido, a título personal, declinar el ofrecimiento que Bergnes le ha hecho de asociarse a ellos en esta empresa. El 17 de diciembre se lo cuenta a López Soler:

He recibido la carta del amigo Bergnes a quien contesto. No dudo que pudiera sernos de alguna utilidad, pero la diversidad de lenguas en que con tanto acierto se ha ejercitado hace que su castellano no sea del más correcto y castizo: así soy del parecer de que reservemos su cooperación para otras cosas que exijan menos aquellas cualidades, y esto aun sujetándolo a una castigada corrección. Hoy le escribo alegándole varias causas que existen realmente y nos privan de admitir sus estimables ofrecimientos. 


\section{EI lento desarrollo del proyecto}

Las llamadas a la urgencia por parte de Aribau estaban justificadas. Recordemos que en el momento en que Sanponts le dio a conocer el plan económico de la empresa ya estaban traducidos los dos primeros tomos y la mitad del tercero, de los cuatro que tenía Ivanhoe.

El 5 de noviembre no se había adelantado nada. López Soler no había acabado de traducir el tercer tomo, y Gallego no había comenzado el cuarto. Tampoco López Soler había escrito todavía el artículo para el Correo Literario que le había encargado Aribau.

Éste, el 22 de ese mes, había empezado a traducir El oficial aventurero en dos tomos, de acuerdo con su idea de preparar obras en reserva. Pero un problema surgido con Gallego en esos días pone en duda que éste vaya a encargarse de la traducción del cuarto tomo ${ }^{18}$, y Aribau se ofrece a hacerlo, aunque «no me atrevo a meter la hoz en el Ivanhoe: no quisiera ofender en lo más mínimo a dicho amigo, y así hasta que esté declarado que él no traducirá el tomo $4^{\circ}$ no tocaré de él cosa alguna).

Pues bien, el 29 de noviembre no solo continuaba inconcluso el tercer tomo de Ivanhoe, sino que todavía no habían llegado los dos primeros a manos de Aribau. Éste, impaciente, reitera su ofrecimiento: «Si debo yo traducir el $4^{\circ}$ [tomo de Ivanhoe] cuida de remitírmelo en francés; pues aquí no tengo más que el original, y sobre él solo no puedo quedar seguro del acierto. Pero sea pronto; para aprovechar algunos vacíos que ahora me dejan mis ocupaciones, y las próximas Pascuas», escribe a Sanponts. Y añade que el traductor de La desposada, con el que ha concertado una entrevista, tiene, para colmo de males, casi terminada la traducción de El oficial aventurero, la misma obra en la que Aribau estaba trabajando.

El 3 de diciembre, cuando continúa sin terminar la traducción del tercer tomo de Ivanhoe, surge una nueva dificultad: Juan Nicasio Gallego se ve obligado a abandonar Barcelona, trasladándose a un pueblo de Valencia. Tres días después, cuando Gallego ya se ha marchado, Sanponts por fin le dice a Aribau que será López Soler quien traducirá el cuarto tomo, pues «no parece regular que meta otro la hoz, como tú decías, y que López lo haga no lo extrañarás.

La lentitud era desesperante. El 14 de diciembre, Aribau todavía no había recibido los dos primeros tomos de Ivanhoe, y Sanponts le anunciaba que le iba a enviar también la traducción de la primera parte del tomo tercero -sólo la primera parte y en sucio-para que la mandara copiar en limpio.

${ }^{18}$ La situación de Gallego en esos momentos era delicada. Se encontraba en Barcelona de forma semi-clandestina, y se ganaba la vida como traductor, utilizando diversos seudónimos: cf $r$. Freire López: 1999. 
El ritmo de Aribau era muy distinto. El 20 de diciembre estaba terminando El oficial aventurero, y pedía que le enviaran Kenilworth para traducirlo, pues tenía dificultades para conseguirlo en Madrid.

A principios de enero de 1829 recibe, por fin, la segunda parte del tercer tomo, pero continúa sin traducirse el cuarto. Y el 25 de febrero, cuando ya saben que el Padre Prior de la Pasión, en quien confiaban, ha puesto pegas a la licencia de los dos primeros tomos, seguía sin concluirse la traducción de la obra, porque López Soler había estado enfermo ${ }^{19}$.

Desde el 22 de abril, en que Aribau escribe a Sanponts: «Yo tengo preparado y puesto en limpio el Oficial aventurero, y traducidos los dos primeros tomos del Kenilworth, para echar mano de ellos inmediatamente de saltado este barranco», no hay más cartas de Aribau.

Sanponts es el primero que claudica (3-VI-1829), dispuesto a refundirlo todo, pero no obtiene contestación de Aribau. El 22 de julio insiste, pidiéndole que retire del Juzgado de Imprentas la solicitud y los ejemplares presentados a la censura. $Y$, por si fuera poco, le cuenta que López Soler también se ha marchado a Valencia, sin haber terminado la traducción del cuarto tomo.

Por las posteriores cartas de Sanponts sabemos que Aribau no hizo lo que le pidió. Todavía el 5 de noviembre Sanponts escribía a un amigo para que recogiera en su nombre los ejemplares del Juzgado de Imprentas, lo que tampoco se llevó a cabo, pues el 26 de mayo de 1830 , Sanponts insistía de nuevo a Aribau en la recuperación de los originales que había presentado a la censura.

\section{Aribau y las novelas ya traducidas}

Este fue el desarrollo de los acontecimientos. Leyendo estas cartas resulta evidente que en el fracaso de esta empresa editorial la censura negativa de Ivanhoe solo fue un escollo que añadir a un proyecto mal llevado. La traducción de la única obra con que lo emprendieron, Ivanhoe, nunca estuvo terminada, y no corrieron el riesgo de preparar un caudal de traducciones en reserva, como había aconsejado Aribau. La lentitud de los traductores, los problemas de Gallego, que finalmente hubo de abandonar Barcelona, la marcha de López Soler sin haber

${ }^{19}$ López Soler debía de estar pasándolo mal por aquellas fechas, y no sólo por problemas de salud. Aribau le comentaba a Sanponts el 24-XII-1828: «Según tengo entendido por medio de algún amigo que ha venido de ésa, López no se halla muy abundante de medios. La conducta que con tanto desinterés ha guardado este amigo con la empresa me parece le hace acrecdor a alguna consideración: nadie trabaja con gusto y acierto, si no tiene cierta tranquilidad de espíritu incompatible con un extremado punto de estrechez. Por lo cual, si te parece podría socorrérsele a cuenta de su trabajo con alguna cosa, alomenos con la mitad del precio convenido, que ya se le aseguró a todo evento. Ya dije y lo repito que para esto y cuanto me corresponda por $\mathrm{mi} 1 / 3$ no tenéis que hacer más que insinuaros para disponer el apronto de lo que fuere». 
terminado su trabajo, y el miedo al riesgo de Sanponts, dieron al traste con el proyecto.

Pero Aribau no se rindió. Sabemos que el 22 de abril de 1829 tenía terminada y puesta en limpio su traducción de El oficial aventurero, traducción de la que Elías de Molíns decía no tener noticia de que hubiera llegado a imprimirse. Y sabemos también que Aribau tenía intención de publicarla: «Por Dios el Ivanhoe que se arregle como pueda; pues si no, voy a concluir el Oficial para dar el primero. A fines de diciembre puedo darlo a la censura, y me parece que a mediados de enero podéis contar sobre él», había escrito a Sanponts el 29 de noviembre de 1828.

Aribau estaba dispuesto a rentabilizar sus esfuerzos, y creo que hay indicios suficientes para suponer que se encuentra detrás de la solicitud de un tal Gregorio Morales Pantoja, que en agosto de 1830 intentaba que la censura aprobara los dos primeros tomos de una traducción de Ivanhoe. Este mismo Gregorio Morales figura como traductor de El oficial aventurero ${ }^{20}$, que en 1831 se publicaba en la Imprenta de Bueno y Librería de la Viuda de Razola, el «honrado y puntualísimo Razola» de esta correspondencia ${ }^{21}$.

Las peripecias del intento de publicación de Ivanhoe por Gregorio Morales Pantoja ante el Consejo Real las relató con detalle González Palencia (1927), pero sin relacionar este caso con el de Aribau del que me vengo ocupando.

Extractando los hechos principales del artículo de González Palencia encontramos que Gregorio Morales Pantoja, no por sí mismo, sino representado por Manuel Domínguez y Ponce, presenta al Consejo Real los dos primeros tomos de Ivanhoe -sólo los dos primeros tomos-, y solicita el permiso de impresión. E1 12 de agosto de 1830 la Sala de Gobierno pasa la instancia a los fiscales, que remiten la obra a la Real Academia de la Historia, la cual, según un auto del Consejo, a partir del 20 de octubre siguiente debe censurar esta clase de obras. El 19 de noviembre la Academia se excusa, alegando que esa obra no es de su competencia, de modo que el Consejo la envía a la Vicaría Eclesiástica de la villa el 10 de diciembre. Pero el 31 de enero la Vicaría Eclesiástica enviaba al Consejo la copia literal del censor al que le habían encomendado censurar esta obra, que también se excusaba de hacerlo por no ser censor de oficio, lo que le eximía de dar su opinión particular, que siempre le comprometería. El 3 de febrero la Sala de Gobierno decide enviar el expediente a los fiscales, quienes el 6 de marzo dicen que compete al Vicario Eclesiástico censurar la obra, por otros o por sí mismo. Así

${ }^{20}$ El oficial aventurero: episodio de las Guerras de Montrose: cuentos de mi huésped por sir Walter Scott; dados a luz por Jedediah Cleishbotham: traducidos al español por Gregorio Morales. Madrid: Imprenta y Librería de Bueno, 1831, 2 volúmenes.

${ }^{21}$ Se trata, además, de una traducción del francés, lengua de la que traducía Aribau, que no dominaba la lengua inglesa. 
que el Consejo, a mediados de marzo, decide dar noticia del caso al Subdelegado General de Imprentas.

Morales Pantoja, ante tanto retraso, reclama al Consejo Real, pero cuando van a pasar su instancia a los fiscales se encuentran con que éstos han despachado por fin el expediente. «El Consejo comunicó (15 de marzo) su decisión al Vicario de la Villa y al Juzgado de Imprentas para los efectos de la censura». Finalmente, con fecha 30 de mayo de 1831 se negaba la licencia para imprimir y publicar esa traducción de Ivanhoe, y se explicaban detalladamente los motivos, que coinciden sustancialmente con los que impidieron la publicación del Ivanhoe presentado por Aribau en enero: la pintura del Prior del Císter, la del Templario, y las expresiones irreverentes sobre la Sagrada Escritura o sobre los santos.

Para probar lo que supongo - que esa traducción era la misma que habían hecho Gallego y López Soler, y que detrás de Gregorio Morales estaba Aribausería necesario localizar el manuscrito de esa traducción, que en 1901 todavía se encontraba en Zamora, en poder de los herederos de Gallego (González Negro 1901, pág. 24), y que hoy por hoy está perdida. Se podrían así cotejar muchos fragmentos literales de esa obra, reproducidos en el texto de la censura, con los de la traducción de Gallego.

\section{Walter Scott en castellano, después del proyecto}

Alrededor de 1830 muchos otros editores españoles habían descubierto el filón de Walter Scott. En 1829 en la imprenta de la viuda e hijos de Brusi, en Barcelona, se editaba la Visión de don Rodrigo, y Moreno en Madrid publicaba la novela histórico-poética Matilde de Rockeby, al mismo tiempo que Cabrerizo - «ese Cabrerizo» de la carta del 6 de diciembre- editaba en Valencia Las páginas de oro de Sir Walter Scott que, traducidas por Juan Nicasio Gallego, eran un extracto de la vida de Napoleón Bonaparte escrita por el escocés ${ }^{22}$.

Fue al comienzo de la década de 1830 cuando tuvo lugar el gran despegue editorial con el proyecto de la Nueva colección de novelas de Sir Walter Scott traducidas por una sociedad de literatos, editada en Madrid por Moreno: los ocho primeros volúmenes, de los veinte que se editaron, aparecieron en 1830: $\mathrm{La}$ dama del lago, con Los desposorios de Triermain y El valle de San Juan ocupa los tomos 1 y 2; el tomo 3 lo constituye El espejo de la tía Margarita con El aposento entapizado y Clorinda o el collar de perlas; El Lord de las islas ocupa el

${ }^{22}$ Según el testimonio el Marqués de Molíns, uno de los fieles amigos que tuvo Gallego, éste «después de haber gozado pingües prebendas eclesiásticas y de haber ocupado distinguido lugar en los escaños legislativos, perseguido a la sazón con injustificable rigor, vivía estrechamente con el producto de su pluma. Tenía hecho ajuste con el editor Cabrerizo para traducir a tanto el pliego (...)») (Molíns 1874, 102). 
cuarto tomo, y los tomos 5, 6, 7 y 8 corresponden a El pirata. En 1831 salió Las cárceles de Edimburgo en cuatro tomos -volúmenes 9, 10, 11 y 12 de la colección-; Ivanhoe en otros cuatro -volúmenes 13, 14, 15 y 16-; y El anticuario en los cuatro últimos de la colección.

En 1830 publicaba Gaspar en Barcelona la Vida de Napoleón Bonaparte, y Gimeno en Valencia, al año siguiente, El castillo de Kenilworth, a la vez que Bueno editaba en Madrid El oficial aventurero ya mencionado; en 1832 se publicaban en Madrid Carlos el temerario o Ana de Geierstein y Woodstock o El caballero de historia, por Jordán, que en 1836 editaría Kenilworth y La hermosa joven de Perth o el día de San Valentín, el mismo año que Oliva, en Barcelona, publicaba los seis tomos de Waverley o sesenta años ha. Dos años después editaba Sancha Guy Mannering o El astrólogo, traducido por Eugenio de Ochoa.

Por su parte, Bergnes de las Casas, cuya colaboración había rehusado Aribau, iniciaba en 1833, en Barcelona, una Biblioteca de Damas con obras de Walter Scott en su mayoría, y ya un año antes había editado El enano misterioso. En la Biblioteca de Damas, Ivanhoe ocupa los cinco primeros volúmenes; El oficial aventurero ${ }^{23}$ el sexto y el séptimo; los cinco tomos de Redgauntlet abarcan hasta el duodécimo; Quintin Durward ocupa del trece al diecisiete; le sigue Roberto, conde de París hasta el tomo veintiuno; y El anticuario ocupa del 26 al 30 . Los tomos 22, 23, 24 y 25 corresponden a la única novela que no es de Walter Scott, El bravo: novela veneciana, de Fenimore Cooper. En 1837 Bergnes sacaría Rob Roy, y en 1838 El talismán y Los puritanos de Escocia, pero ya no en la Biblioteca de Damas.

En la década de los 40 Mellado tomó en Madrid el relevo en las ediciones de Walter Scott: La maga de la montaña (1844), Juana de Lewardeen (1844) y Las fortunas de Nigel (1845); al tiempo que en Barcelona lo hacían Oliva -Las aguas de San Román (1843) y El monasterio (1845)-, Piferrer -The lay of the last minstrell (1843)-, y Sauri, que en 1844 editaba El enano misterioso.

No son las únicas ediciones, pero pasada la década de los 40 apenas se publicaron nuevas obras de Walter Scott, aunque continuaron reeditándose las que habían tenido más éxito entre el público español.

\section{Para concluir}

De todo lo expuesto, creo que pueden extraerse unas cuantas hipótesis, si no conclusiones.

\footnotetext{
${ }^{23}$ Resulta curioso comprobar que el orden de la colección de Bergnes es exactamente el mismo del proyecto de Aribau: comienza con Ivanhoe y continúa con El oficial aventurero.
} 
La primera de ellas es el nexo entre proyecto catalán y el de Alzine, al haber tomado el testigo de la publicación de las obras completas de Walter Scott que éste abandonó, aunque con un planteamiento de más corto alcance: «La Empresa no se aventurará por ahora más que a la publicación del Ivanhoe», había escrito Sanponts.

Es otra la que me lleva a entrever a Aribau detrás de Gregorio Morales Pantoja-seudónimo u hombre de paja-, traductor de El oficial aventurero, publicado por la imprenta de Bueno y Librería de Razola en 1831, después de haber intentado, sin éxito, a mediados de 1830 , la licencia para los dos primeros tomos de Ivanhoe ${ }^{24}$. Esto explicaría la insistencia de Sanponts en que Aribau retirara los tomos presentados a la censura y que se los remitiera, cosa que Aribau mal podía hacer si estaba intentando conseguir la licencia por otro camino.

$\mathrm{Y}$ finalmente una pregunta queda en el aire, y es qué Walter Scott recibieron aquellos españoles del siglo XIX que no pudieron leerlo en versión original. Desde luego no fue el mismo que conocieron los lectores de lengua inglesa. En parte, porque los editores estaban dispuestos a mutilar y modificar, sin que les dolieran prendas, los textos originales para conseguir la licencia de impresión, pero también para hacer más accesibles aquellas obras en las que, a juicio de Aribau, los lectores españoles «encontrarán obscuros unos pasajes, impertinentes otros, y pesadísimos sus más hermosos diálogos». A lo que hay que añadir que muchas de esas traducciones al castellano se hacían a partir del francés, por traductores que no dominaban la lengua de Walter Scott. Todo lo cual invita a cotejar las traducciones españolas con los textos originales, no sólo para conocer un estadio de la historia de la traducción en España, como a veces se hace, sino para saber realmente qué Walter Scott llegó a los españoles de los años románticos.

${ }^{24}$ Gregorio Morales aparece también como traductor de otras dos obras: Manual del Legista ó Coleccion de diversos opúsculos de jurisprudencia por [André Marie Jean Jacques] Dupin; traducida al castellano con adiciones y correcciones acomodada a nuestras leyes por Gregorio Morales Pantoja; con un discurso sobre el estudio de la jurisprudencia patria. Madrid: [s.n.], 1829 (Imp. de Pedro Sanz) VIII, 356; $15 \mathrm{~cm}$. y Dirección general de cartas en forma de diccionarto: para escribir a todas las ciudades de toda España adicionado y corregido por el que escribió Bernardo Espinalt y Garcia; y notablemente mejorado por José Freire y Gregorio Morales Pantoja. Madrid: Imprenta de Pedro Sanz, se hallará en su librería, 1835, 2 vols. 


\section{BIBLIOGRAFÍA}

Allegra, Giovanni, 1980. La viña y los surcos (Las ideas literarias en España del XVIII al XIX), Sevilla, Universidad.

CHURCHMAN Ph. y E. A. PEERs, 1922. «A survey of the influence of Sir Walter Scott in Spain», Revue Hispanique, LV, págs. 227-310.

Elías DE Molins, Antonio, 1889. Diccionario biográfico y bibliográfico de escritores y artistas catalanes del siglo XIX, Barcelona, Giró, 2 vols.

Freire López, Ana Ma , 1999. «Juan Nicasio Gallego, traductor», en Francisco

LAFARGA (ed.) La traducción en España (1750-1830). Lengua, Literatura,

Cultura, Lleida, Edicions de la Universitat de Lleida, págs. 521-528.

GonZÁleZ NEGro, Eliseo, 1902. Estudio biográfico de don Juan Nicasio Gallego,

Zamora, Establecimiento Tipográfico de San José.

GonzÁlez PALENCIA, Ángel, 1927. Walter Scott y la censura gubernativa, Madrid,

Imprenta Municipal. (Recogido después en Entre dos siglos. Estudios literarios. Segunda serie, Madrid, CSIC, 1943, págs. 277-310.)

MARRAST, Robert, 1988. «Ediciones perpiñanesas de Walter Scott en castellano:

1824-1826», Romanticismo 3-4 (Génova), págs. 69-80.

Milá y FONTANALS, Manuel, 1893. «Moral literaria: contraste entre la escue-

la escéptica y Walter Scott», en Obras completas, V, Opúsculos literarios, Barcelona.

Molins, Marqués de, 1874. Piquer y sus amigos, Madrid, Tello.

MONTESINOS, José F., 1955. Introducción a una historia de la novela en España, en el siglo $X I X$, seguida del Esbozo de una bibliografía española de traducciones de novelas (1800-1850), s. 1., Castalia.

Montolí, Manuel de, 1936. Aribau i la Catalunya del seu temps, Barcelona, Institut d'Estudis Catalans.

NÚÑEZ DE ARENAS, Manuel, 1925. «Simples notas acerca de Walter Scott en

España), Revue Hispanique, LXV, págs. 153-159 (Recogido después en L'Espagne des Lumières au Romantisme, Paris, Centre de Recherches de l'Institut d'Etudes Hispaniques, 1964, págs. 363-368.)

Olives CANAls, Santiago, 1947. Bergnes de las Casas, helenista y editor (18011879), Barcelona, CSIC.

PEERS, E. A., 1926. «Studies in the influence of Sir Walter Scott in Spain», Revue Hispanique, LXVIII, págs. 1-160.

PlCOCHE, J. L., 1980. «Ramón López Soler, plagiaire et précurseur», Bulletin Hispanique, LXXXII, págs. 81-93.

Rubio Cremades, Enrique, 1992. «La narrativa de Ramón López Soler: Ficción y realidad», Romance Quarterly, 39 (febrero), págs. 17-21.

RUMEAU, A., 1949. Mariano José de Larra et l'Espagne à la veille du romantisme, tesis mecanografiada, París. 
WHITE, Henry Adelbert, 1927. Sir Walter Scott's novels on the stage. (Yale Studies in English LXXVI), New Haven, Yale University Press.

ZELLARS, G. G., 1931. «Influencia de Walter Scott en España», RFE, XVIII, págs. 149-162. 